\title{
Ruptura gástrica idiopática en niño preescolar. Informe de un caso
}

\author{
Idiopathic gastric rupture in toddler. Case report
}

\author{
Dr. Alejandro Donoso Fuentes ${ }^{a, b}$, Dra. Daniela Arriagada Santis ${ }^{b}$, Dr. Pablo Cruces Romero ${ }^{a}$ y \\ Dr. Franco Díaz Rubio ${ }^{a}$
}

\begin{abstract}
RESUMEN
La ruptura gástrica idiopática es una patología muy poco frecuente en niños. La gran mayoría de los casos ocurre en el período neonatal. Comunicamos el caso de una paciente preescolar de 2 años, sexo femenino, sin antecedentes mórbidos. Consultó con antecedente de $48 \mathrm{~h}$ de dolor abdominal, náuseas y vómitos. Ingresó al servicio de urgencia en malas condiciones generales, con un abdomen distendido y signos de irritación peritoneal. Se realizó laparotomía exploradora de emergencia que reveló ruptura gástrica en pared posterior ocasionada por múltiples perforaciones. Se efectuó gastrectomía parcial. Ingresó a UCI en shock. Recibió asistencia ventilatoria mecánica, reanimación con fluidos ( $260 \mathrm{ml} / \mathrm{kg}$ en $12 \mathrm{~h}$ ), fármacos vasoactivos y tratamiento antibiótico con cefotaxima-metronidazol. El laboratorio evidenció leucopenia y trombopenia. El estudio etiológico fue negativo para ingesta de tóxicos y medicamentos. Se descartó colagenopatía y su gastrinemia fue normal. Su postoperatorio se caracterizó por persistencia de fiebre originada por colección subfrénica izquierda (cultivo positivo para Candida galabrata). Se realizó limpieza quirúrgica mediantelaparotomía y drenaje percutáneo de las colecciones residuales. Completó tres semanas de terapia antibiótica y antifúngica con evolución satisfactoria. El control ambulatorio de la paciente a los 12 meses fue normal.

Palabras clave: perforación gástrica, preescolar, Candida spp.
\end{abstract}

\section{SUMMARY}

Idiopathic gastric rupture is rare in children. Most of them occur in newborn. The authors report the case of a 2-year-old female toddler with no significant medical records. Clinical picture began $48 \mathrm{~h}$ before with abdominal pain, nausea and vomiting. She was admitted to the Emergency Room in poor general condition, with abdominal distension and rebound tenderness. Laparotomy was performed immediately showing multiple perforations in the posterior wall of the stomach. Partial gastrectomy was performed. Afterwards, she was admitted to ICU in shock. She received mechanical ventilation,

a. Área de Cuidados Críticos. Unidad de Gestión Clínica del Niño. Hospital Padre Hurtado. Santiago, Chile.

b. Programa de Medicina Intensiva en Pediatría.

Facultad de Medicina Clínica Alemana.

Universidad del Desarrollo. Santiago, Chile.

\section{Correspondencia:}

Dr. Alejandro Donoso F.:

adonoso@hurtadohosp.cl

Conflicto de intereses: Ninguno que declarar.

Recibido: 23-9-11

Aceptado: 19-10-11 intravenous fluid administration $(260 \mathrm{ml} / \mathrm{kg}$ in $12 \mathrm{~h})$, vasoactive support and antibacterial therapy (cefotaxime and metronidazole). Laboratory showed leukopenia and thrombocytopenia. Etiological study was entirely negative for toxic and drug consumption. Collagen disease was ruled out and serum level of gastrin was normal. Her post operative course was characterized by persistent fever caused by left subphrenic collection (positive culture for Candida galabrata). Peritoneal lavage via laparotomy and percutaneous drainage of the residual collections were performed. She completed 3 weeks of antibacterial and antifungal therapies with adequate outcome. Her followup in 12 months was uneventful.

Key words: gastric rupture, toddler, Candida spp.

http:/ /dx.doi.org/10.5546/aap.2012.e21

\section{INTRODUCCIÓN}

La ruptura gástrica es un cuadro que se ha descrito como causa de catástrofe intraabdominal, que puede ocasionar shock y muerte del paciente. ${ }^{1}$ La ruptura gástrica idiopática es infrecuente en niños más allá del período neonatal y, en ocasiones, ocurre en adultos. ${ }^{2}$ En pacientes pediátricos no neonatos se han propuestos diversos factores etiológicos, pero en la mayoría su origen sigue siendo desconocido. Nuestro objetivo es comunicar un caso de ruptura gástrica idiopática en una niña de dos años de edad, donde revisamos signos, síntomas, consideraciones diagnósticas y terapéuticas de esta entidad.

\section{CASO CLÍNICO}

Paciente preescolar de 2 años de edad, sexo femenino, sin antecedentes mórbidos ni familiares destacables. Consultó con historia de 48 h de dolor abdominal, náuseas y vómitos previo a su ingreso. El Servicio de Urgencia de otro hospital objetivó deshidratación moderada e hiperémesis, que requirió hidratación parenteral y observación por $12 \mathrm{~h}$. Se envió a su domicilio en buenas condiciones, con diagnóstico de gastroenteritis de probable etiología viral; sin embargo, evolucionó con persistencia de náuseas y vómitos. Ingresó a nuestro servicio de urgencia en malas condiciones generales, temperatura de $39^{\circ} \mathrm{C}$ axilar, taquicárdica (200 lat/min), hipotensa (73/54 mmHg), con mala perfusión periférica, pulsos débiles, saturación $95 \%$ con $\mathrm{FiO}_{2}$ ambiental. A la inspección destaca- 
ba un abdomen distendido y tenso, sin evidencias de traumatismos. Al examen se encontró signos de irritación peritoneal sin ruidos hidroaéreos. Por gravedad del cuadro no se efectuó radiografía de abdomen. Se realizó laparotomía exploradora de emergencia encontrándose abundante líquido libre de aspecto purulento y ruptura gástrica en pared posterior de fondo y cuerpo, asociada a múltiples perforaciones (Figura 1). Se efectuó gastrectomía parcial. No se detectaron otras anomalías gastrointestinales. Ingresó a UCI en shock séptico. Recibió asistencia ventilatoria mecánica, reanimación con fluidos $260 \mathrm{ml} / \mathrm{kg} / 12 \mathrm{~h}$ y fármacos vasoactivos (norepinefrina $0,1 \mu \mathrm{g} / \mathrm{kg} / \mathrm{min}+$ dobutamina $3 \mu \mathrm{g} / \mathrm{kg} / \mathrm{min}$ ). Se empleó tratamiento antibiótico con cefotaxima $150 \mathrm{mg} / \mathrm{kg} /$ día y metronidazol $30 \mathrm{mg} / \mathrm{kg} /$ día. Los exámenes de laboratorio revelaron acidosis metabólica $(\mathrm{pH} 7,1$ BE-13 mmol/1), electrólitos plasmáticos normales, leucopenia de $4700 \mathrm{~mm}^{3}$ (32\% segmentados) y trombopenia de $117000 \mathrm{~mm}^{3}$. La paciente no presentó disfunción de órganos los días siguientes, extubándose al cuarto día de evolución.

Su postoperatorio se caracterizó por persistencia de fiebre y ascenso de proteína C-reactiva. Control ecográfico en la segunda semana de evolución, negativo para colecciones. Los hemocultivos seriados y el urocultivo fueron negativos.

Figura 1. Hallazgos intraoperatorios. Múltiples perforaciones gástricas (flecha) en la pared posterior, en paciente de dos años de edad con ruptura gástrica idiopática.

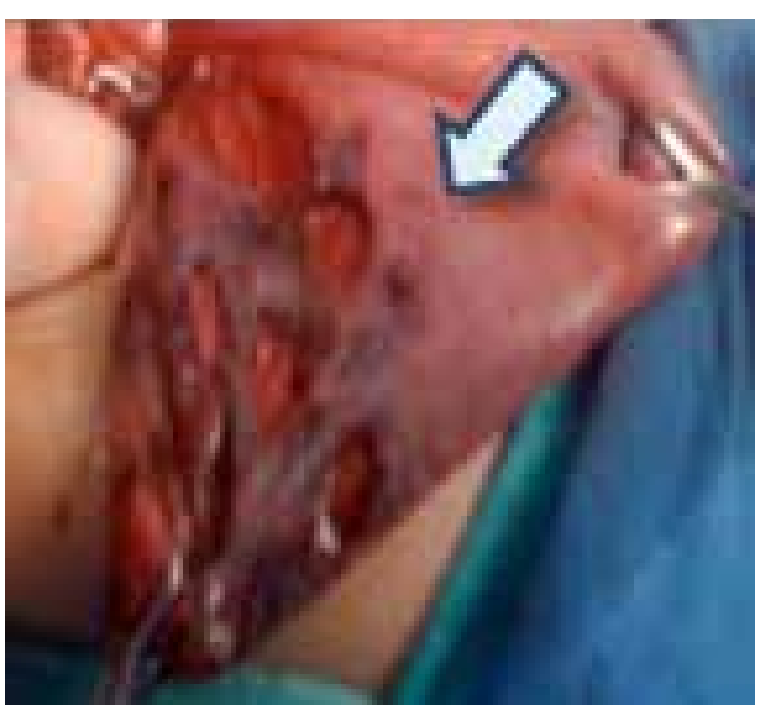

Ecocardiografía normal. El día 14, la ecografía abdominal mostró colección subfrénica izquierda de $4 \times 1 \mathrm{~cm}$. Se realizó limpieza quirúrgica mediante laparotomía. El cultivo fue positivo (líquido peritoneal y colección) para Candida galabrata sensible a voriconazol. Se modificó terapia antibiótica a vancomicina $40 \mathrm{mg} / \mathrm{kg} /$ día - meropenen $60 \mathrm{mg} /$ $\mathrm{kg}$ / día y se adicionó voriconazol $15 \mathrm{mg} / \mathrm{kg} /$ día, completando tres semanas. El tratamiento de esta colección residual fue con drenaje percutáneo, que se mantuvo por tres días, con buena respuesta. La ecografía de control no mostró colecciones residuales.

La histopatología de la pieza operatoria reveló pared gástrica con presencia de úlceras gástricas activas en etapa de granulación. Sin evidencia de malignidad, necrosis transmural, inflamación aguda, defecto muscular o trombosis.

En el estudio complementario para la causa de la ruptura gástrica se descartó antecedente de traumatismo previo, como también ingesta de ácido-álcali, hierro o algún otro tipo de medicamento (salicilato). La gastrinemia fue de $65 \mathrm{pg} /$ $\mathrm{ml}(\mathrm{N}:<100 \mathrm{pg} / \mathrm{ml})$. El estudio inmunológico resultó normal (inmunoglobulina, complemento y subpoblaciones linfocitarias). El estudio de colagenopatías fue asimismo normal.

La paciente fue dada de alta de UCI a los 32 días. Se efectuó endoscopia de control a las seis semanas de evolución, que mostró estómago amplio y distensible. Zona de pared posterior con cicatriz y engrosamiento en relación a sutura. Mucosa de aspecto normal.

Alta hospitalaria a los 47 días, con omeprazol. Evolucionó en forma satisfactoria y con buen incremento pondoestatural. Control ambulatorio a los 12 meses con paciente asintomática y adecuado desarrollo.

\section{DISCUSIÓN}

La perforación gástrica ocurre en la mayoría de los casos en neonatos y en ocasiones en población adulta, pero rara vez en niños. ${ }^{2}$ Habitualmente, las perforaciones gástricas en adultos son secundarias a úlcera péptica ${ }^{1}$ o tumor, ${ }^{3}$ mientras que en los neonatos existen factores de riesgo asociados a esta entidad, con asfixia, prematurez, isquemia, ausencia congénita de la musculatura gástrica o aumento de la presión intraluminal. ${ }^{1}$

En pacientes pediátricos se han descrito causas secundarias de perforación gástrica no traumáticas, como úlcera péptica ${ }^{4}$ o gastritis eosinofílicas, ${ }^{5}$ o traumáticas, como maniobra de $\mathrm{Heimlich}^{6}$ (compresión abdominal utilizada para la obstrucción 
de vía aérea), sonda nasogástrica o ventilación a presión positiva. Además se han comunicado casos de ruptura gástrica asociados con trastornos genéticos neurodegenerativos que cursan con disfunción orofaríngea y dismotilidad gástrica como el síndrome de $\operatorname{Rett}^{7} \mathrm{y}$, recientemente, en pacientes con síndrome heterotáxico ${ }^{1} \mathrm{y}$ neuropatía motora. ${ }^{5}$

Habitualmente, la pared anterior es la más afectada $(40 \%)$, seguida por la curvatura mayor $(23 \%)$, curvatura menor $(15 \%)$ y pared posterior (15\%). Sin embargo, esta distribución depende del grupo etario por analizar, y la curvatura mayor es la más afectada en los pacientes no neonatos. ${ }^{8}$

Su patogenia no está del todo dilucidada, pero existe evidencia sugerente de que la presión intraluminal elevada puede jugar un rol importante en el mecanismo subyacente de este cuadro. En algunos casos, el estatus convulsivo o el maltrato físico han sido comunicados antes de la perforación, lo que podría estar relacionado con una elevación de la presión intragástrica. No obstante, por las características de la ruptura (forma y sitio), se han propuesto otros mecanismos responsables. Algunos autores sugieren que la lesión sería secundaria a una sobredistensión gástrica con la consiguiente vasoconstricción y obstrucción al flujo que finalmente resulta en isquemia y necrosis. ${ }^{9}$

La presentación clínica suele ser inespecífica, con síntomas muy frecuentes de observar en pacientes pediátricos y debe considerarse como diagnóstico diferencial ante dolor súbito y distensión abdominal, signos peritoneales o compromiso hemodinámico, todo lo cual constituye una emergencia quirúrgica.

Se ha descrito una serie de hallazgos radiológicos sugerentes de ruptura gástrica; incluyen ausencia de niveles hidroaéreos gástricos, con aire normal o disminuido en intestino delgado y grueso, y signos de neumoperitoneo. ${ }^{1}$

Hasta la presente revisión, los casos comunicados de perforación gástrica espontánea en pacientes pediátricos fuera de la etapa neonatal, ${ }^{10,11}$ han revelado ciertas características comunes, como una mayor incidencia en mujeres y predominio en raza asiática, que el sitio más comúnmente afectado es la curvatura mayor de la pared posterior, y que un porcentaje importante de pacientes tenía antecedente de infección respiratoria alta o administración de medicamentos previamente. ${ }^{10}$

En el caso aquí comunicado, el hallazgo de tejido de granulación en las úlceras de la pieza operatoria sugiere el transcurso de un tiempo previo a la perforación, no pareciendo probable que éstas fueran secundarias a enfermedad péptica, dada su ubicación, la ausencia de gastritis en la histología, ni haber detectado Helicobacter pylori.

En nuestro caso, los cultivos de líquido peritoneal y colección intraabdominal resultaron positivos para Candida galabrata; sin embargo, no se logró demostrar invasión fúngica en la histopatología. La relevancia de la infección por Candida $s p p$. en la perforación gástrica radica en que, en algunos informes se asocia a este patógeno como factor etiológico; ${ }^{12}$ pero, no se ha demostrado que tenga la capacidad de invadir en forma primaria la mucosa gástrica y, ocasionar por sí misma, este tipo de lesión. ${ }^{13}$ Es sabido que las perforaciones gastrointestinales tienen un aumento en la incidencia de infecciones por Candida spp en forma secundaria, lo cual a su vez es un factor de mal pronóstico asociado a morbimortalidad.

El pronóstico de la ruptura gástrica espontánea es generalmente bueno con un tratamiento quirúrgico apropiado. No obstante, el retraso del diagnóstico se asocia con un mal pronóstico y aumento de la mortalidad. ${ }^{14}$

\section{CONCLUSIÓN}

La perforación gástrica espontánea es infrecuente en preescolares. Su presentación clínica es inespecífica, por lo que se debe tener un alto índice de sospecha, ya que es una entidad potencialmente letal, que debe considerarse entre los diagnósticos diferenciales de catástrofe intraabdominal.

\section{BIBLIOGRAFÍA}

1. Aronson D, Ellison A. Spontaneous gastric perforation in a child with heterotaxy syndrome. Pediatr Emerg Care 2010; 26:925-7.

2. Shimizu T, Horiuchi T, Hirooka S, Yonekura T, Tamai H. Idiopathic gastric rupture in a 3-month-old girl. Acta Paediatr 2003; 92:628-30.

3. Bellantone R, Lombardi CP, Rubino F, Ricci R, Capelli A. Spontaneous gastric rupture and hemoperitoneum due to gastric hemangioma. Dig Dis Sci 2001; 46:852-853.

4. Grosfeld JL, Molinari F, Chaet M, Engum SA, et al. Gastrointestinal perforation and peritonitis in infants and children: Experience with 179 cases over ten years. Surgery 1996; 120:650-6.

5. Rubio I, Vásquez F, Ibarra de la Rosa I, López E, Velasco M. Perforación gástrica en paciente con neuropatía motora. An Pediatr 2011; 75:152-4.

6. Gallardo A, Rosado R, Ramírez D, Medina P, et al. Rupture of the lesser gastric curvature after Heimlich maneuver. Surg Endosc 2003; 17:1494-500.

7. Shah MB, Bittner JG 4th, Edwards MA. Rett syndrome and gastric perforation. Ann Surg 2008; 74:315-7.

8. Tejerina Álvarez E, Holanda M, López-Espadas F, Domínguez MJ, et al. Gastric rupture from blunt abdominal trauma. Injury 2004; 35:228-31. 
9. Hon $Q$, Huijun $Y$, Jinze Z. Gastric rupture caused by acute gastric distention in non neonatal children: clinical analysis of 3 cases. Chin Med J 2000; 113:1147-9.

10. Libeer F, Vanhamel N, Huyghe M, Verlinden E. Spontaneous gastric rupture in non-neonatal children: Acase report. Acta Chir Belg 2007; 107:560-3.

11. Adachi $Y$, Takamatsu H, Noguchi H, Tahara H, et al. Spontaneous rupture of the stomach in preschool age children: A report of two cases. Surg Today 1998; 28:79-8.
12. Faure M, Brancho E, Yánez C, Barragan L. Gastric perforation with Candida tropicalis invasion in a previouly healthy girl. Mycoses 1997; 40:175-7.

13. Rodea H, López S, Aristi G, Athié C, Pérez E. Sepsis abdominal por necrosis y perforación gástrica por Candida spp.: a propósito de un caso. Cir Gen 2009; 31:56-61.

14. Holgersen LO. The etiology of spontaneous gastric perforation ofthe newborn: a re-evaluation. J Pediatr Surg 1981; 16:608-13. 